\title{
Analysis of the Dynamic Relationship Between Consumption Expenditure and Economic Growth in Somalia: Co-integration and Vector Error Correction Modelling
}

\author{
Abdikani Abdullahi Sheikdon \\ Faculty of Social Science, Department of Economics, Sakarya University, Sakarya, Turkey
}

\begin{abstract}
In this study, it has been reviewed the recent empirical studies to provide fresh evidence of the causal and dynamic relationship between the consumption expenditure and economic growth in Somalia. The study covers the sample period of 1970-2018. After determining that both series were integrated of order (1), Engle-Granger two stage cointegration test and vector error correction model has been employed. The findings of the study revealed that, consumption expenditure and economic growth have both long run and short run relationship. The error correction model performs well, as it has been negative and statically significant, signifying that each year adjustments towards the convergence is ascertained. However, the vecm based Granger causality test indicated that there's a unidirectional short run relationship running from consumption expenditure to economic growth.

Keywords: Consumption expenditure, Unit root test, co-integration, Vector error correction, GDP, Granger causality, Error correction model.

DOI: $10.7176 / \mathrm{JESD} / 10-14-05$

Publication date:July $31^{\text {st }} 2020$

Introduction

The argument that growth in consumption stimulates the economy of a country could be better comprehended by referring back to the underlying economic theories as one would ask how consumption boosts the economy. A principal way to measure a country's economy is to compute its overall productivity or economic activities by gross domestic product GDP and when it is dichotomously observed its components, consumption expenditure constitutes a big share and its ups and downs have an immediate impact on the GDP. Consumption of the nondurable goods constitute the bigger portion of the economies in the under-developed and developing countries, while the durable goods are consumed by upper class consumers that could be said they dominantly live in the developed countries. Now that the more the people consume, the already supplied goods and services finishes earlier, then the producers manage to meet the demand of the people by producing more and more which in turn creates a multiplier effect as each additional production line will demand hiring new workers.

A report published by the Aid coordination unit, office of the prime minister of the federal republic of Somalia in April 2017 points out that Somalia's growth is consumption driven, citing that since Somalia is highly aid dependent, and the aid flows as well as the remittances together fuel the country's consumption, which is indeed a plausible elucidation. Therefore the paper attempts to test if consumption expenditure co-move together with economic growth in the long run and also estimate the short run dynamics of the said variables.
\end{abstract}

\section{Literature review}

Numerous empirical studies have been made, discussing the dynamic relationship between consumption expenditure and gross domestic product. Irrefutably, the findings might have been diverse depending on the countries being studied and the period.

Using panel data analysis of Asian countries, Hae Kim (2017) investigated the effect of consumption on economic growth and identified six patterns of Asian economic growth which are: consumption-driven; exportled; oil rich/resources; employment saving-based; government spending; and domestic investment. However in his findings he found that consumption-driven and export-led economies positively affect the economies of the Asian countries that were analyzed. .

Sarah \& Ayidegbon (2011) utilized time series data that spans from 1980 to 2010 and employed co-integration and vector error correction approach to estimate the long run and short run dynamics of the government expenditure on defense and economic growth in Nigeria and their result revealed that there's positive long run as well as short run relationship between them, Though in the variance decomposition analysis their results indicated that the military sector contributes slightly to growth of the other sectors in the analyses.

P. K. MISHRA (2011), applied Johansen co-integration and Granger causality test to detect if there's a causal relationship between real consumption expenditure and the GDP in India. Using a sample period of 1950-51 to 2008-09, the results exposed that there's long run equilibrium relationship between the real consumption expenditure and the GDP. However the causality analyses found that there's unidirectional causal relationship in the long run, running from the real consumption expenditure to the economic growth, but didn't detect short run 
causality between them

CHRISTINE (2015), conducted a study that aims to estimate the relationship between public expenditure and economic growth of Kenya using a sample period that ranges from $1963-2012$. The applied econometric method was Johansen co-integration approach and vector error correction model and the findings showed that public expenditure components co-move together with the economic growth in the long run and the error correction term had a magnitude speed adjustment of $3.6 \%$. A unidirectional causation has been found between public expenditure and the economic growth.

Wanissa Suanin (2015) analyzing quarterly data from 1993-2016, the researcher examined the effects of different types of government expenditures on economic growth in Thailand, and employed different econometric techniques to estimate the long and short run effects of the different sectors of public expenditure on economic growth. The results showed that budgetary expenditure has the potential to stimulate economic growth in the long run, while an excess budgetary expenditure and the quasi fiscal spending can also encourage the economic growth in the short run.

According to Renuka \& John (2007), reinvestigating the energy consumption- GDP growth nexus while collecting the sample data of twenty net energy importing and exporting countries in the period of 1971 to 2002. The researchers employed a panel error correction model and discovered that both in the long and short run there was a bidirectional causality between energy consumption and economic growth in the developed countries, while in the emerging economies only in the short run, stimulating economy by energy consumption has been detected.

Abdul, Zulkefly, Bakri \& Riayati (2010) with their intention to get an empirical evidence in the role of household consumption and fixed investment in influencing the economic growth, they used the econometric technique of the structural vector error correction approach. The empirical results revealed that household consumption and fixed investment have positive significant influence in the output growth in the short run.

Similarly, Xi-xiang Sun \& Ling-li Deng (2013) revisited the household consumption and economic growth nexus and using Johansen co-integration approach and Granger causality test conducted a study on household consumption's impact on the economic growth of Hubei province in China from the period of 1980 to 2010. The results revealed that in the long run there's a stable relationship between household consumption and economic growth. Also the conclusion of the causality analysis showed that the economic growth of Hubei province granger causes household consumption. Using a multivariate co-integration approach the researchers adopted a sample period data from 1961 to 2013 and analyzed the macroeconomic determinants of the household consumption expenditure in Ghana to capture the long run and short run determinants. The co-integration analysis revealed that there was a significant long run relationship between real household consumption expenditure and real exchange rate and real economic growth. Also the variance decomposition analysis and the Granger causality analysis indicated that in the short run only price level changes affect the household consumption.

Cătălina MOTOFEI (2017), choosing eastern area of the EU and Romania as the area of the study, the researcher used panel regression and analyzed the most recent trends in the evolution of the gross domestic product of the chosen panel in the Eastern Europe from the 2014Q1 to 2016Q4. The results exposed that the major contributors in the GDP of the analyzed panel were; the final consumption expenditures of the households and also Non-profit institutions serving households (NPISH), recording a contribution of up to $63.39 \%$ in the last quarter of the analyzed interval in Romania.

Daniel Landau (1983), conducted a cross country study attempting to estimate the relationship between government expenditure and economic growth of a panel that composes 104 countries. The researcher decomposed the panel into three groups panel A, B and $\mathrm{C}$ with different time intervals. The findings suggested that there was a statistically significant negative relationship between the share of government expenditure in GDP and the rate of GDP per capita growth.

Emre, Dilek \& Hassan (2017) Testing the health-led growth hypothesis for Turkey, the researchers used bond test method, autoregressive-distributed lag approach (ARDL) and Kalman filter modelling in the sample period of 1975 to 2013. Their findings supported the health-led hypothesis and found that a $1 \%$ increase in the health expenditure will lead the GDP per capita to increase by $0.434 \%$, indicating that there's positive relationship between the health expenditure and the economic growth.

\section{Data and Methodology}

The used data in the analysis has been sourced from the United Nations statistics division (UNSD). Reflecting data availability the time interval of the data is annual and spans from 1970 to 2018 . Therefore both series consumption expenditure and Gross domestic product (GDP) have got equal series of 49 years with no missing data in the specified time. The variables has been taken their logarithmic form since the data showed high variance and large dispersion. Both series have been taken their constant dollar values in the year 2015. The methodology used in the study comprises of sequence of steps beginning with testing the stationarity of the series, co-integration testing, estimating the error correction model, specification of the vector error correction model and the testing of Granger causality. The whole data analysis will be done with the help of the E-views 10 econometric software. 


\section{Unit root test}

For co-integration analysis, it is important to check the unit roots at the outset to ascertain whether the modeled variables are I (0) at levels and I (1) at differences. Macroeconomic series often are not stationary at level and if used when I (0), it would lead a spurious regression. Table 1 presents the results of the unit root test using the Augmented Dickey Fuller (ADF) test and for robustness and consistency purpose, it has also been conducted Philips-Perron's unit root test. ADF and PP equations can be specified the following form respectively:

$$
\begin{gathered}
\Delta X=\alpha+\gamma_{t}+\alpha X_{t_{-1}}+\beta \sum_{i=1}^{m} \Delta X_{t_{-1}}+e_{t} \\
\Delta X_{t_{-1}}=\alpha+\delta X_{t_{-1}}+\mu_{t}
\end{gathered}
$$

On the first equation dependent variable $\mathrm{X}$ is being explained by its lagged values plus deterministic terms, constant and trend. Unlike the DF equation, ADF equation is included the lagged versions of the dependent variable to overcome the autocorrelation problem. While the PP equation makes modification to the t-statistics of coefficient $\delta$ to eliminate serial correlation in the $\mu_{t}$ (disturbance term).

The tests were applied to each variable over the annual period of 1970-2018 at levels and at their first differences. The test results are compared against the critical values for the rejection of the null hypothesis of no unit root. The below table shows the output:

\begin{tabular}{|c|c|c|c|c|}
\hline \multirow[b]{2}{*}{ Variable } & \multicolumn{2}{|c|}{ Level } & \multicolumn{2}{|c|}{ First difference } \\
\hline & ADF & PP & ADF & PP \\
\hline LOGGDP & -1.440106 & -1.687172 & $-7.181007^{2}$ 水水 & $-7.196055^{\text {水水水 }}$ \\
\hline LOGCEX & -1.614896 & -1.539966 & $-7.368919 * * *$ & $-7.472199 * * *$ \\
\hline
\end{tabular}

Table1: Results of the Unit root tests

Note $* * *$ denotes significance at $\% 5$ level

Table: 1 shows that both tests concluded the same result as all variables are integrated of order one I (1) in levels and of order zero I ( 0$)$ in first differences, meaning that they are non-stationary in levels and stationary in first differences.

\section{Co integration test}

If each series becomes stationary after taking its differences and the linear combinations of these series are also stationary, the series in the analysis are said to be co integrated (Engle-Granger, 1987) . Co integration, which means long-term equilibrium, means that the residuals of the variables are stationary. The use of the series in their stationary level results consistent estimates and the concern of the spurious regression disappears.

The method used in the study is a two-stage co integration test developed by Engle and Granger (1987). The Engle-granger approach works well and detects the co-integration in the case of analyzing two variables. When the predictors are more than one, the alternative approaches like Johansen co-integration method is applied. Accordingly, static OLS is estimated among the variables in their level stage. The predicted OLS is the equation that reflects the long-term relationship. In the second stage, the residuals are obtained from the co integration equation. Here the residuals represent the linear combination of the variables and are tested their stationary degree as a separate series. If the obtained residual's result shows that they do not contain unit root or in other words stationary at level, a long-term relationship can be mentioned between the series. The first stage regression takes the following form:

$$
Y_{t}=\alpha+\beta x_{t}+e_{t}
$$

Here the traditional ADF critical values can be used as a rough guide, but for aptness in the case of the Two stage Engle-Granger approach for co-integration, the T-statistics of the unit root test of the residuals obtained are compared with the one proposed by Engle \& Yoo (1987). If the computed T-statistic value $>$ the Engle \& Yoo Tstatistic, then it is said that the variables under consideration are co-integrated and have a long run relationship.

Table2: Unit root test result of the obtained residuals

\begin{tabular}{lllcc}
\hline Series & ADF T-statistic & $\begin{array}{l}\text { Engle \&Yoo } \\
\text { Critical values }\end{array}$ & Lag length & $\begin{array}{l}\text { Order of } \\
\text { Integration }\end{array}$ \\
\hline$\hat{e}_{\mathrm{t}}$ & $-4.677793^{* * * *}$ & -1.95 & 0 & $\mathrm{I}(0)$ \\
\hline
\end{tabular}

Note*** Significance at \%5 level

As the result depicts the ADF T-value $>$ than the Engle-Yoo T-values, then it has met the co-integration 
condition since the residuals are stationary at level $\mathrm{I}(0)$, and the null hypothesis of no co-integration is rejected at $5 \%$ level. Therefore it can be concluded that the series are co-integrated and have a long run relationship.

\section{Error correction model specification}

Now that the series are co integrated the specification of the dynamic model could be the second step while including the lagged version of the residuals that represent the long run behavior of the series. The model could be specified as follows:

$$
\Delta \log G D P_{t}=\alpha+\beta_{1} \Delta \log C O N S_{t}+\gamma E C T_{t_{-1}}+e_{t}
$$

Where $\Delta$, is the first difference operator of the series, $\alpha$ is a constant term, $\beta_{1}$ indicates the short run coefficient parameter for the consumption expenditure, $E C T_{t_{-1}}$ is the lagged residuals from the co-integrating regression and $e_{t}$ denotes the disturbance term. Here " $\gamma$ " represents the long run coefficient parameter that adjust the disequilibrium. It should be negative and significant to satisfy the error correction term condition.

$$
\begin{aligned}
& \Delta \operatorname{LogGDP} P_{t}=0.0074+0.469 \Delta \operatorname{LogCON}_{t}-0.528 E C T_{t_{-1}}+e_{t} \\
& \text { T-statistic: }[0.994] \quad[4.4007] \quad[-4.3558] \\
& \text { Adjusted } R^{2}=39 \\
& (0.3253) \quad(0.0001) * * * \quad(0.0001) \\
& \text { DW: } 2.0
\end{aligned}
$$

\section{Source: Author's calculations}

Notes: *** indicates 5\% significance level. The values given in the square brackets are the t-statistics values. Also those values in the round brackets are the p-values.

From the outcome of the above computations, a Durbin Watson value of 2, clearly indicates that the model does not suffer from autocorrelation problem, and also the predictors used in the estimation explained the change in GDP by $39 \%$ as adjusted $R^{2}$ points.

As the regression output shows the error correction mechanism is performing well as its coefficient is negative and strongly significant which indicates that it has satisfied the condition of the error correction term. This means that the divergence from the long run equilibrium is not permanent and each year about $\% 53$ of the long run disequilibrium is adjusted. Assuming the ceteris paribus, this disequilibrium of the variables under consideration will disappear after approximately 2 years.

\section{Vector Error Correction Model}

The existence of co integration among the variables in the analysis, demands the specification of the vector error correction model to capture the short run dynamics and VECM based causality test. Thus, the fitted vector error correction model could have the following form:

$$
\begin{aligned}
& \Delta \log G D P_{t}=\beta_{0}+\sum_{J=1}^{M} \beta_{1_{j}} \Delta \log G D P_{t_{-j}}+\sum_{J=1}^{H} \beta_{2_{j}} \Delta \operatorname{LogCONS}_{t_{-j}}+\alpha E C T_{t_{-1}}+u_{t} \\
& \Delta \operatorname{LogCONS}_{t}=\delta_{0}+\sum_{J=1}^{L} \delta_{1_{j}} \Delta \operatorname{LogCONS}_{t_{-j}}+\sum_{J=1}^{Q} \delta_{2 j} \Delta \operatorname{LogGDP}_{t_{-j}}+\gamma \operatorname{ECT}_{t_{-1}}+v_{t}
\end{aligned}
$$

Where $\Delta \log G D P_{t}, \Delta \log C O N S_{t}$ are the Logged and first differences of the gross domestic product and consumption expenditure variables respectively, $\mathrm{U}$ and $\mathrm{V}$ are serially uncorrelated error terms. $\mathrm{M}, \mathrm{H}, \mathrm{L}$ and $\mathrm{Q}$ are all the lag lengths determined by the AIC, SC and HQ lag selection criterions. $E_{t_{-1}}$ And $E C T_{t_{-1}}$ are the lagged version of the error correction terms which had been obtained from the residuals of the variables. The $\beta_{s}$ and $\delta_{s}$ are the coefficient parameters of the short run dynamics of the variables. Also $\alpha$ and $\gamma$ are the error correction term coefficients for the short-run adjustment correcting long run disequilibrium in dependent variables in each period. The results of the vector error correction model estimates are given in the below table: 
Table3: Vector error correction estimates

\begin{tabular}{cccc} 
Regressors & Coefficients & T-statistic & P-value \\
\hline Model one: Dependent variable: $\Delta$ LogGDP & & & \\
\hline DLOGGDP(-1) & 0.427732 & 2.631684 & 0.0122 \\
DLOGGDP(-2) & 0.326877 & 2.267506 & 0.0291 \\
DLOGGDP(-3) & 0.389041 & 3.266826 & 0.0023 \\
DLOGCON(-1) & -0.569203 & -3.493699 & 0.0012 \\
DLOGCON(-2) & -0.244671 & -1.685853 & 0.1000 \\
ECT $(-1)$ & -0.711939 & -3.848953 & 0.0004 \\
Constant & 0.010930 & -1.107842 & 0.1848 \\
\hline Model two: Dependent variable: DLogCons & & & \\
\hline DLOGCONS(-1) & & & \\
DLOGGDP(-1) & -0.005101 & -0.025927 & 0.9794 \\
DLOGGDP(-2) & -0.036672 & -0.180016 & 0.8581 \\
DLOGGDP(-3) & 0.201351 & 1.276170 & 0.2094 \\
ECT $(-1)$ & 0.320878 & -2.043883 & 0.0478 \\
Constant & 0.160225 & 0.806468 & 0.4249 \\
\hline
\end{tabular}

Source: Author's calculations. Note: In both models, the lag length in the parenthesis are determined according to AIC, SC and HQ criterions

As the vector error correction regression result shows, even in the short run the error correction term $\left(E C T_{t_{-1}}\right)$ is performing well as it has satisfied the condition of the ECT. This indicates that the imbalance in the short is also resolved about \% 71 each year.

Engle-Granger two-stage co-integration test results have ascertained that there's a long run relationship between consumption expenditure and gross domestic product. However, co-integration test does not give any information about the direction of the existing relationship between variables. Determining the direction of the relationship between the variables is possible with the Granger causality test. Considering the trait that Granger causality tests are very sensitive to lag lengths and it is a perquisite to determine the lag length before conducting the test. The lag lengths has been already determined on the stage of the vecm specification.

Therefore in the sense of the granger causality from both equations 4 and 5, the null hypothesis $H_{0}$ of Cons does not granger cause GDP could not be rejected, if $\beta_{2}=\alpha=0$ and the $H_{0}$ of GDP does not granger cause Cons if $\delta_{2}=\gamma=0$.

Regarding the causality test results are given in Table 4.

Table 4: VECM based Granger causality test

\begin{tabular}{llcc}
\hline Null hypothesis & F-Statistic & P-values & Decision \\
\hline DLOGCON does not Granger cause DLOGGDP & 6.123530 & 0.0050 & Reject \\
DLOGGDP does not Granger cause DLOGCON & 1.868231 & 0.1509 & Accept
\end{tabular}

Note: Lags included for the $1^{\text {st }}$ hypothesis were 2 and 3 lags for the $2^{\text {nd }}$ hypothesis.

As can be seen from Table 4, with 2 lags, the null hypothesis of DLOGCON does not Granger DLOGGDP has been rejected at the $5 \%$ significance level. On the other hand, using 3 lags, it could not being rejected the null hypothesis of $D L O G G D P$ does not Granger cause DLOGCON. Meaning that in the short run DLOGCON is the cause of the $D L O G G D P$, but not the vise verse. The overall conclusion is that there a unidirectional causal relationship running from $D L O G C O N$ to $G L O G G D P$.

\section{Conclusion and recommendation}

In this paper, the dynamic relationship between consumption expenditure and economic growth in the case of Somalia from 1970-2018 has been examined through co-integration and vector error correction approach. For a healthy estimates, the analyses has been started with testing the order of integration of the series to avoid spurious regression. The unit root tests have demonstrated that both series were I (1). The results of the co-integration and vecm exposed that there's both long run and short run relationship. As expected disequilibrium between the two series would be the case, however the functionality of the error correction term gets ride-off the worry for these 
imbalances to stay last. Therefore in both short run and long run disequilibriums the coefficient of the error correction term was negative and statistically significant, meaning that adjustment of the imbalances is assured.

In the light of the empirical evidences, the study recommends the policy makers to embolden policies that lead to productivity increase, since the relationship holds both in the long and the short run, an increase in consumption expenditure will drive the production sectors to produce more to meet the market demand, thus eventually boosting the overall economy. The study suggests to the potential researchers in the field, the inclusion of more predictors in to model to avoid the omitted variable bias, as this study is only confined to one predictor variable.

\section{References}

Aid Flows in Somalia, Analysis of Aid flow data (2017). Aid Coordination Unit Office of Prime Minister Federal Republic of Somalia. 1-10.

Dickey, D. A., \& Fuller, W. A. (1979). Distribution of the estimators for autoregressive time series with a unit root. Journal of the American statistical association, 74(366a), 427-431.

Engle, R. F., \& Granger, C. W. (1987). Co-integration and error correction: representation, estimation, and testing. Econometrica: journal of the Econometric Society, 251-276.

Kim, H. S. (2014). Journal of Global Economics. Journal of Global Economics, 2(10.4172/2375), 4389-1000113.

Anyanwu, S., \& Aiyedogbon, J. O. C. (2011). Defence expenditure and economic growth in Nigeria: A vectorerror correction model (VECM) approach. Asian Journal of Empirical Research, 1(2), 31-40.

Mishra, P. K. (2011). Dynamics of the relationship between real consumption expenditure and economic growth in India. indian Journal of economics \& Business, 10(4), 553-563.

CHRIS, I. (2015). Explaining the Relationship between Public Expenditure and Economic Growth in Kenya using Vector Error Correction Model (VECM). International ournal of Economic Sciences, 4(3), 19-38.

Suanin, W. (2015). The impact of government expenditure on economic growth in Thailand (Doctoral dissertation, Faculty of Economics, Thammasat University).

Mahadevan, R., \& Asafu-Adjaye, J. (2007). Energy consumption, economic growth and prices: A reassessment using panel VECM for developed and developing countries. Energy policy, 35(4), 2481-2490.

Abdul Karim, Z., Abdul Karim, B., \& Ahmad, R. (2010). Fixed investment, household consumption, and economic growth: a structural vector error correction model (SVECM) study of Malaysia.

Sun, X. X., \& Deng, L. L. (2013). An Empirical Analysis on the Influence of Household Consumption on Economic Growth in Hubei Province. In The 19th International Conference on Industrial Engineering and Engineering Management (pp. 41-51). Springer, Berlin, Heidelberg.

Bonsu, C. O., \& Muzindutsi, P. F. (2017). Macroeconomic determinants of household consumption expenditure in Ghana: a multivariate co-integration approach. International Journal of Economics and Financial Issues, $7(4)$.

Motofei, C. (2017). Vectors of economic growth in the eastern area of the EU. Theoretical and Applied Economics, 24(1), 610.

Landau, D. (1983). Government expenditure and economic growth: a cross-country study. Southern Economic Journal, 783-792.

Atilgan, E., Kilic, D., \& Ertugrul, H. M. (2017). The dynamic relationship between health expenditure and economic growth: is the health-led growth hypothesis valid for Turkey? The European Journal of Health Economics, 18(5), 567-574. 